AGH DRILLING, OIL, GAS • Vol. 34 • No. 1 • 2017

http://dx.doi.org/10.7494/drill.2017.34.1.169

Rafał Wiśniowski*, Krzysztof Skrzypaszek*, Piotr Kiebzak*

\title{
ECD OPTIMIZATION WITH SPECIALLY DESIGNED LOW RHEOLOGY DRILLING FLUIDS**
}

\section{INTRODUCTION}

Nowadays petroleum is one of the most important commodities, which plays a major role in energy and transportation industries. In order to meet a huge demand for oil there is a need to replace mature fields with new ones. But while modern projects are far more technically advanced there is a need to create new technologies to successfully reach the reservoirs. As oil and gas industry moves toward more difficult, ultra-deep projects, drilling problems may occur more often and that is why avoiding complications plays a increasingly vital role. One of the conditions and ways to achieve a effective and non-failure drilling process is to maintain a proper mud pressure during all operations. Therefore ECD management is one of the most crucial aspects and optimization of the parameter is very important. For that reason a new solution is presented to help reducing ECD value and optimize the parameter with low rheology drilling fluids.

\section{THEORETICAL INTRODUCTION}

Under dynamic conditions, when mud pumps are on, drilling fluid circulating in wellbore annulus exerts higher pressure on formations than hydraulic pressure. Equivalent Circulating Density (ECD) then is a effective mud density exerted against the formation that takes into account the influence of pressure losses of the fluid flowing up the annulus as well as changes of the fluid's average density due to rock cuttings load

* AGH University of Science and Technology, Faculty of Drilling, Oil and Gas, Krakow, Poland

** Work performed within the statutory program of the Faculty of Drilling, Oil and Gas, AGH University of Science and Technology No. 11.11.190.555 
and combines it with initial mud weight [10]. ECD parameter represents the additional superficial 'mud weight' increase caused by pressure losses of fluid in the annulus. In other words ECD is the density a static fluid needs to have in order to create the same pressure the actual fluid creates while circulating in the annulus at a certain depth.

The Equivalent Circulation Density parameter is commonly expressed in ppg or $\mathrm{kg} / \mathrm{m}^{3}$ and its basic equation is presented below [9]:

$$
\mathrm{ECD}=\mathrm{MW}+\frac{\Delta P}{0.0981 \cdot \mathrm{TVD}}
$$

where:

$$
\begin{aligned}
\text { MW } & \text { - mud weight } / \text { density }\left[\mathrm{kg} / \mathrm{m}^{3}\right] \\
\text { TVD } & - \text { true vertical depth }[\mathrm{m}] \\
\Delta P & - \text { pressure loss }[\mathrm{Pa}]
\end{aligned}
$$

$\Delta P$ describes only pressure losses in annulus between drill string and borehole without pressure losses inside drill string.

It is vital to highlight that $\Delta P$ value is calculated by different equations, depending on selected part of the annulus:

a) non-casted section [6]:

$$
\Delta P=0.824 \cdot 10^{-6} \cdot \frac{\eta^{0.14} \cdot \mathrm{MW}^{0.86} \cdot Q^{1.86} \cdot \mathrm{MD}}{\left(d_{1}-d_{2}\right)^{0.86} \cdot\left(d_{1}^{2}-d_{2}^{2}\right)^{2}}
$$

b) cased section [6]:

$$
\Delta P=0.771 \cdot 10^{-6} \cdot \frac{\eta^{0.14} \cdot \mathrm{MW}^{0.86} \cdot Q^{1.86} \cdot \mathrm{MD}}{\left(d_{1}-d_{2}\right)^{0.86} \cdot\left(d_{1}^{2}-d_{2}^{2}\right)^{2}}
$$

where:

$$
\begin{aligned}
\eta & - \text { plastic viscosity }[\mathrm{Pa} \cdot \mathrm{s}] \\
Q & - \text { flow rate }\left[\mathrm{m}^{3} / \mathrm{s}\right] \\
\mathrm{MD} & - \text { measured depth or wellbore length }[\mathrm{m}], \\
d_{1} & - \text { wellbore diameter }[\mathrm{m}], \\
d_{2} & - \text { drill pipe outside diameter }[\mathrm{m}] .
\end{aligned}
$$


Therefore combination of above mentioned equations may present full ECD formula:

a) non-casted section:

$$
\mathrm{ECD}=\mathrm{MW}+(0.0981 \cdot \mathrm{TVD})^{-1} \cdot 0.824 \cdot 10^{-6} \cdot \frac{\eta^{0.14} \cdot M W^{0.86} \cdot Q^{1.86} \cdot \mathrm{MD}}{\left(d_{1}-d_{2}\right)^{0.86} \cdot\left(d_{1}^{2}-d_{2}^{2}\right)^{2}}
$$

b) cased section:

$$
\mathrm{ECD}=\mathrm{MW}+(0.0981 \cdot \mathrm{TVD})^{-1} \cdot 0.771 \cdot 10^{-6} \cdot \frac{\eta^{0.14} \cdot \mathrm{MW}^{0.86} \cdot Q^{1.86} \cdot \mathrm{MD}}{\left(d_{1}-d_{2}\right)^{0.86} \cdot\left(d_{1}^{2}-d_{2}^{2}\right)^{2}}
$$

Despite chosen scenario, logical sense of both formulas is the same. Therefore it is acceptable to simplify the equations in order to present better dependences between particular factors This will help to understand ECD parameter itself and whole process of calculations as well. In equation (6) $a$ is a constant which represents $0.0981^{-1} \cdot 0.824 \cdot 10^{-6}$ or $0.0981^{-1} \cdot 0.771 \cdot 10^{-6}$ and all exponents of used variables. Obviously, the simplified version has only demonstrative from and cannot be applied in any calculations:

$$
\mathrm{ECD}=\mathrm{MW}+a \cdot \frac{\eta \cdot \mathrm{MW} \cdot Q \cdot \mathrm{MD}}{D \cdot \mathrm{TVD}}
$$

where:

$$
\begin{aligned}
& a-\text { constant }[-], \\
& D-\text { annulus diameter }[\mathrm{m}]
\end{aligned}
$$

Simplified version of the full formula plainly presents which parameters affect ECD. By analyzing this equation it is easy to notice how particular factors impact the parameter's value, for instance it is obvious that $\mathrm{MW}$ is the most important element and its changes will make the biggest difference in ECD value. What is more, despite that the equation presents series of parameters such as:

- wellbore geometry - annular clearances,

- true vertical depth (TVD), measured depth (MD),

- rheology, mud properties: plastic viscosity,

- flow rate. 
It is necessary to remember that they are more coefficients which impact ECD value like [7]:

- rhelogoy, mud properties: yield point,

- rate of penetration (ROP),

- drill sting rotary speed,

- wellbore trajectory,

- hole cleaning process.

As it is presented above, along with other factors, both plastic viscosity and yield point impact ECD value. Therefore the this paper is fully committed to investigate how mud rheology may influence ECD management and help to prevent drilling problems and complications in demanding wellbore pressure conditions.

\section{RESEARCH METHODOLOGY}

The whole research conducted by the authors is based on real, field data from two existing wells. The wellbores were chosen in a way to have similar design, trajectory, completion, drilling and hydraulics parameters. Both wells were drilled in Lublin Basin (Poland) in order to estimate potential of shale hydrocarbons accumulations in this area. For that reason wellbores have also similar lithology with targeted, most perspective formations located in Lower Silurian and Upper Ordovician shales.

Wellbore A: intermediate $95 / 8^{\prime \prime}$ casing was run down to $2179 \mathrm{~m}$ depth. Kick off point was set in open hole $81 / 2^{\prime \prime}$ section at $2640 \mathrm{~m}$ TVD in order to reach $91 \mathrm{deg}$ inclination targeting end of curve at $3161 \mathrm{~m} \mathrm{MD/2961} \mathrm{m} \mathrm{TVD.} \mathrm{Once} \mathrm{the} \mathrm{trajectory} \mathrm{was}$ directed, approximately $1147 \mathrm{~m}$ of horizontal section was drilled, reaching TD at $4307 \mathrm{~m}$ MD/2952 m TVD.

Wellbore B: intermediate $95 / 8^{\prime \prime}$ casing was run down to $2517 \mathrm{~m}$ TVD. Kick off point was set in open hole $81 / 2^{\prime \prime}$ section at $3004 \mathrm{~m}$ TVD in order to reach $91 \mathrm{deg}$ inclination targeting end of curve at $3433 \mathrm{~m} \mathrm{MD} / 3306 \mathrm{~m}$ TVD. Once the trajectory was directed, approximately $1147 \mathrm{~m}$ of horizontal section was drilled, reaching TD at $4385 \mathrm{~m}$ MD/3274 m TVD.

All above mentioned components of the wellbores were designed in Halliburton's Landmark Drilling Software [8]. Pore and fracture pressure gradients were also applied with regard to accomplished geological surveys and then ECD values were calculated for each part of the wellbores [1]. In order to verify the programs results accuracy, the outcomes were compared with pressure while drilling (PWD) equipment surveys' results made during drilling operations. Analyzes indicate that there appeared some differences. The results from Landmark Software grow in stable, continuous way along wellbores length. On the other hand in PWD outcomes increase or drop erratically without any noticeable or repeatable scheme. This situation appears due to a fact that even Landmark Software takes into account various, crucial factors it still uses mathematical 
equations and computer science which produce "linear" results. Wellbore environment instead, is very harsh, unpredictable and unstable ambient, especially for measurement equipment sensors. Nevertheless the differences in results do not exceed $5 \%$ of their total values. For that reason it is permissible and logical to assume that not only ECD values but also conducted simulations, included in this paper are correct and present a proper scientific value.

\section{NUMERICAL SIMULATIONS RESULTS}

Simulations and tests made in Landmark Drilling Software [8] were executed for a situation when the last $81 / 2^{\prime \prime}$ open hole section was drilled and target depth was reached. This wellbore section is usually the most challenging one, where appear many problems or complications and ECD managements is extremely vital there. In the research it was examined how plastic viscosity (PV), yield point (YP) or combination of these parameters changes would affect overall ECD value. PV and YP were modified to their terminal, minimum and maximum, possible values in given conditions [1]. Then ECD parameter was calculated again in order to check differences between primary and modified conditions (Primary fluids' parameters are presented in Tab. 1). Obtained results are similar for both wells and give resembling conclusions.

Both plastic viscosity and yield point are defined as fluid resistance to flow [3]. The first parameter is caused by mechanical friction which appears when one layer of fluid slides by another, while the second is a result of electrochemical or attractive forces arising in a fluid. Allowedly both parameters play a vital role in drilling mud pressure losses calculations [4]. Simply the higher PV or YP is, the bigger pressure losses and ECD should be. Furthermore, high PV may also cause several drilling complications. A chance for differential sticking rises, especially in water base muds, when the PV grow, because of increase in solids content. Additionally high PV may cause difficulties in removing rock cuttings in mud cleaning system [5].

Therefore, it is logical that in conducted simulations PV and YP significantly affected overall ECD value. The results presented in Table 4 and 5 and a description which explains how to properly read the tables and understand all abbreviations are included in Appendix.

Equivalent circulating density changed adequately to decrease or increase of PV and YP. With lower mud rheology parameters, ECD also declined and conversely with higher rheology parameters ECD was also rose. The values changed in stable and regular manner regardless of wellbore section. Furthermore as it was mentioned before, the differences are substantial, maximum ECD reduction reached $0.84 \mathrm{ppg}$. In the last group of simulations, parallel changes of PY and YP obviously resulted in the greatest differences in pressure losses, hence ECD. What is very compelling, it appears that YP may affect ECD much more than PV both in terms of lowering or upgrading the parameter's value. This fact may also indicate that YP have bigger influence on ECD management than PV, but the phenomenon should be taken under further, detailed investigation. 
Ultimately there may appear a conclusion that proper mud rheology treatment could be key solution for successful ECD management in demanding wellbore conditions. Additionally a big advantage of this idea is that mud properties are constantly monitored and can be changed or adjusted anytime to required level, without high costs.

\section{FIELD DATA}

The previous statement is also backed up by following scientific examination. Bolivar, Young et al. [2] conducted a research in order to prepare a project of a world record ERD well, where major drilling complications related to high ECD and lost circulation or extensive circulating and conditioning due to barite sag were expected. According to collected field data, significant reductions in ECD, stand pipe pressures (SPP) and torque were accomplished as special, low rheology fluid was used.

The authors compared previously drilled wells from Hibernia Platform, where conventional API barite weighted synthetic fluid was used with a experimental wellbore that was selected to present the technical advantages of using a specially designed, low rheology, synthetic based drilling fluid. In the experimental wellbore $81 / 2$ " production hole section was $535 \mathrm{~m}$ long and drilled to 6,240 m MD at an inclination angle of $25 \mathrm{deg}$. A unique characteristic of the low rheology drilling fluid applied in the trial well is its use of specially treated, micron sized, barite weight material (TMSB). The nature of the particles in the TMSB fluid system, in their size and treatment, allows the drilling fluid to be designed with lower low-shear rheology and even increased density than the other weight materials without compromising the barite sag performance of the fluid. Despite the higher density the low rheology, TMSB, drilling fluid has demonstrated considerable ECD reduction as well as other technical benefits that have contributed toward reduced drilling risk, without any safety, health, environment or operational issues.

The tests results are very satisfying [2] and Table 2 shows the pump pressures and ECD recorded by the PWD tool at the point of displacing the conventional fluid system to the TMSB system. Additionally, Table 3 presents the fluid properties of the conventional synthetic fluid compared with the TMSB fluid at the time of displacement. Over the complete section drilled the TMSB system gave a 10\% reduction in ECD at an average flow rate $10 \%$ higher and pump pressure $16 \%$ lower in comparison to conventional API barite-weighted synthetic fluid. Furthermore, standpipe pressure was reduced of average $15 \%$ as well as torque which decreased around $30 \%$. What is more there were no indications of poor hole cleaning during the trial section.

\section{CONCLUSIONS}

In the final analysis, Both computer simulations and field tests indicate that mud rheology plays a crucial role and impacts ECD greatly. Therefore mud rheology 
treatment seems to be a remedy for demanding ECD management. This solution is very handful especially in advanced and complicated projects where other parameters as flow rate or fluid density cannot be changed. Nevertheless it is vital to remember, that mud rheology still plays a crucial role in drilling operations, like hole cleaning thus sometimes it should not be reduced or even it may be impossible. Furthermore, what is very compelling simulations' results highlight yield point importance in pressure losses calculations and indicate that the parameter may have equal or even bigger impact on ECD than plastic viscosity, but this phenomenon should be examined during further, detailed, laboratory research.

\section{REFERENCES}

[1] Kiebzak P.: Equivalent circulating density (ECD) value impact on optimization of drill string elements selection process in oil wells. Wydział Wiertnictwa, Nafty i Gazu, 2016.

[2] Bolivar N., Young J. et al.: Field Result of Equivalent-Circulating-Density Reduction with a Low-Rheology Fluid. Society of Petroleum Engineers, 2007.

[3] Wiśniowski R., Skrzypaszek K.: Analiza modeli reologicznych stosowanych $w$ technologiach inżynierskich. Wiertnictwo, Nafta, Gaz, vol. 23, No. 1, 2006, pp. 523-532.

[4] Skrzypaszek K.: Wybrane aspekty inżynierii cieczy plastycznolepkich stosowanych w technologiach wiertniczych. Wydział Wiertnictwa, Nafty i Gazu, 2010.

[5] Mi SWACO.: Engineering Drilling Fluid Manual. 31.III.1998.

[6] Wójcikowski A.: Wykonywanie pomiarów płuczki wiertniczej i specjalnej 311[40].Z2.0. Instytut Technologii Eksploatacji - Państwowy Instytut Badawczy, Radom 2007.

[7] Aadnoy B., Cooper I., Miska S.: Advanced Drilling and Well Technology. Society of Petroleum Engineers, 2009.

\section{Others}

[8] Halliburton Landmark Software Manual (Faculty of Drilling, Oil and Gas at AGH UST License; Quotation NO.: 22159269).

[9] http://www.iwcf.org/images/pdfs/formula_sheets/drilling/QARD7CEV8_English_ Metri_0.0981_Formula_Sheet.pdf (II.2016).

[10] K\&M Technology Group (2015) Training Materials.

\section{APPENDIX}

There are presented numerical simulations results prepared (Tabs 4 and 5) in Landmark Drilling Software. In order to read the data properly, in undermentioned description are con-secutively explained meanings of all titles and abbreviations used in included tables. 
Table 1

Drilling mud properties

\begin{tabular}{|l|c|c|}
\hline \multicolumn{3}{|c|}{ Drilling mud properties } \\
\hline \multicolumn{1}{|c|}{ Properties } & Wellbore A & Wellbore B \\
\hline Density [ppg] & 13.35 & 12.85 \\
\hline PV [cP] & 28 & 36 \\
\hline YP [lbf/100 $\left.\mathrm{ft}^{2}\right]$ & 29 & 27 \\
\hline
\end{tabular}

Table 2

PWD data at displacement

\begin{tabular}{|l|c|c|c|c|}
\hline \multicolumn{5}{|c|}{ PWD Data at Displacement to TMSB System } \\
\hline $\begin{array}{l}\text { Flow } \\
\text { Rate } \\
\text { [gpm] }\end{array}$ & \multicolumn{2}{|c|}{ Pump Pressures [psi] } & \multicolumn{2}{|c|}{ ECD [ppg] } \\
\cline { 2 - 5 } & $\begin{array}{c}\text { API } \\
(11.00 \mathrm{ppg})\end{array}$ & $\begin{array}{c}\text { TMSB } \\
(11.25 \mathrm{ppg})\end{array}$ & $\begin{array}{c}\text { API } \\
(11.00 \mathrm{ppg})\end{array}$ & $\begin{array}{c}\text { TMSB } \\
(11.25 \mathrm{ppg})\end{array}$ \\
\hline 334 & 2062 & 1399 & 11.99 & 11.64 \\
\hline 396 & 2292 & 1808 & 12.01 & 11.65 \\
\hline 529 & 3501 & 2980 & 12.29 & 12.05 \\
\hline
\end{tabular}

Table 3

Drilling fluid properties at displacement

\begin{tabular}{|l|c|c|}
\hline \multicolumn{3}{|c|}{ Drilling Fluid Properties at Displacement } \\
\hline \multicolumn{1}{|c|}{ Type of System } & Conventional & TMSB \\
\hline Density [ppg] & 11.00 & 11.25 \\
\hline PV [cP]/YP [lbs $\left./ 100 \mathrm{ft}^{2}\right]$ & $31 / 14$ & $19 / 7$ \\
\hline Fann35 6\&3rpm at $50^{\circ} \mathrm{C}$ & $9 \& 8$ & $3 \& 3$ \\
\hline ES [V] & 700 & 364 \\
\hline SWR & $82 / 18$ & $80 / 20$ \\
\hline LGS [\%] & 11.7 & 4.3 \\
\hline
\end{tabular}

Where: ES - electrical stability (Volts), SWR - synthetic additives/water ratio, LGS - low gravity solids content 


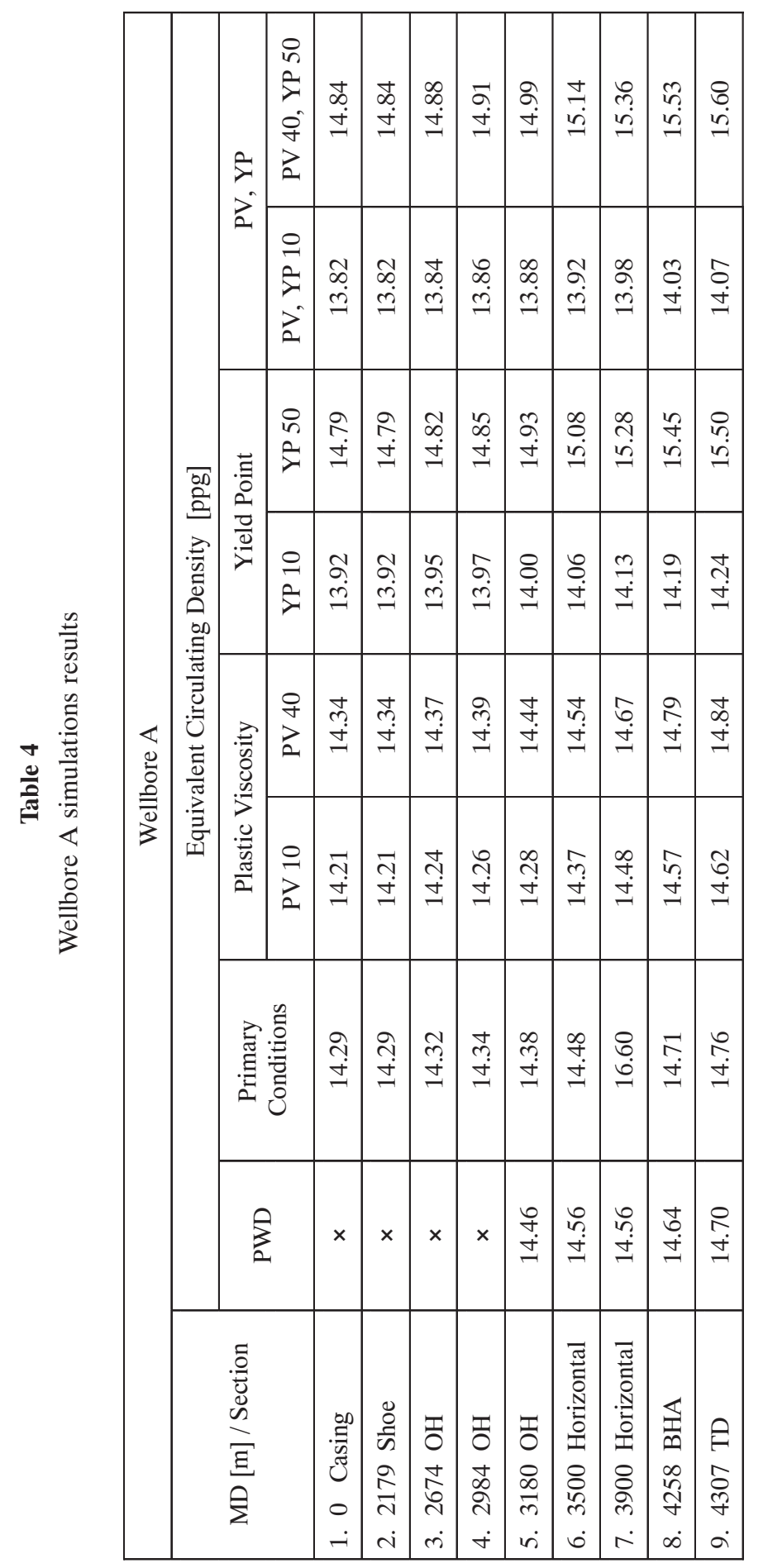




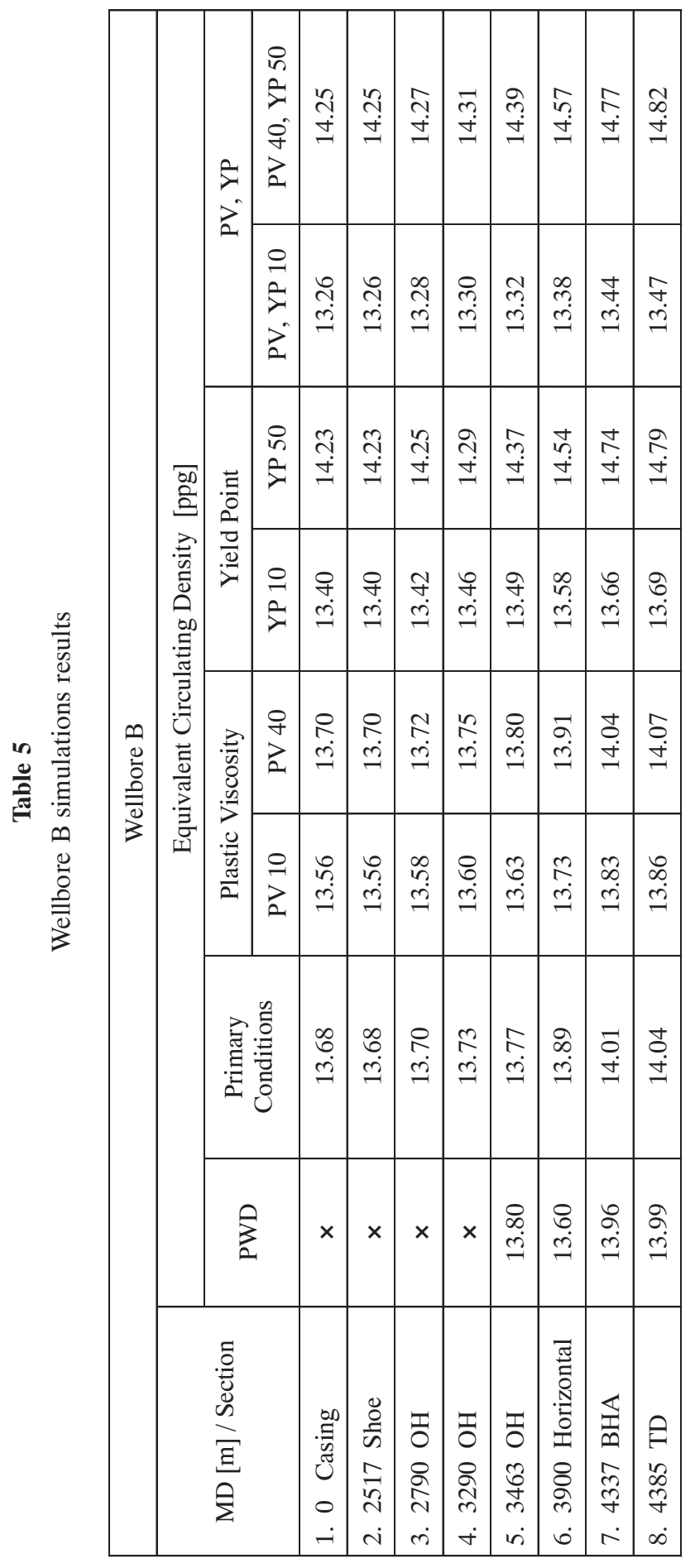


The first column (counting from the left, Tabs 4 and 5) include particular survey points, which were vital from ECD management point of view. Numbers indicate wellbore measured depth (MD) in meters while words and abbreviations present selected part of well. Hence " 0 Casing" means that measurement was made at $0 \mathrm{~m} \mathrm{MD}$ in $95 / 8$ " casing string. "Shoe" always refers to casing shoe of $95 / 8$ " intermediate section. "OH" stands for open hole 8 1/2" section. "3900 Horizontal” means that survey was made in horizontal part of open hole section at $3900 \mathrm{~m}$ of MD. "BHA" regards to wellbore section with bottom hole assembly part of drill string. "TD" indicates that the last measurement point is located in drill bit position at target depth.

In "PWD" column are presented real data surveys from pressure while drilling equipment. X regard to the points where PWD measurements were not made, because this tool was used only in horizontal sections.

"Primary Condition" columns include results from Landmark Drilling Software which presents ECD values in primary well conditions for mud rheology presented in Table 1, without changes or optimizations in any parameter whatsoever. As it was mentioned at the beginning, results from this column were compared with PWD data in order to check the software's accuracy.

The rest of columns are presented mud rheology simulations results. PV or YP are abbreviations of plastic viscosity, yield point, while numbers et. 10 indicate nominal value of particular parameter. $\mathrm{PV}$ is expressed in $[\mathrm{cP}]$, while $\mathrm{YP}$ in $\left[\mathrm{lbf} / 100 \mathrm{ft}^{2}\right]$. The last column include results from simulations where PV and YP were changed simultaneously. 